\title{
RECENT DEVELOPMENT IN CLT CONNECTIONS PART II: IN-PLANE SHEAR CONNECTIONS FOR CLT BRACING ELEMENTS UNDER CYCLIC LOADS
}

\author{
Tobias Schmidt \\ Research Scientist \\ E-mail: tobias.schmidt2@kit.edu \\ Hans Joachim Blaß* \\ Head of Department \\ Timber Structures and Building Constructions \\ Research Centre for Steel, Timber and Masonry \\ Karlsruhe Institute of Technology \\ Karlsruhe, Germany \\ E-mail: hans.blass@kit.edu
}

(Received August 2017)

\begin{abstract}
Because of their high shear strength and stiffness, cross-laminated timber (CLT) members are especially suited for in-plane loads. However, the ductility and energy dissipation capacity of a CLT structure is mainly determined by properties of the mechanical connections such as dowel-type fasteners. Unfortunately, the load-slip behavior of these typical timber-to-timber connections shows pinched hysteresis loops and impairment of strength. For seismic loads, highly dissipative connections with stable dissipation properties are desirable. A new type of connection was developed avoiding the pinching of hysteresis loops while showing high energy dissipation. An experimental investigation and a design proposal of a highly dissipative steel plate connection for CLT shear walls is presented as a result of the work.
\end{abstract}

Keywords: Cross-laminated timber, ductile and dissipative in-plane shear connection, wall and floor diaphragms, bracing elements, shear walls.

\section{INTRODUCTION}

The ductility and energy dissipation capacity of a cross-laminated timber (CLT) structure is mainly determined by the number and properties of the mechanical connections (Ceccotti 1995). Presently, the required energy dissipation capacity for earthquake loading is often achieved by metallic dowel-type fasteners loaded beyond their yield load. Both plastic embedding deformations of the timber and plastic bending deformation of the fastener contribute to energy dissipation. The load-slip curves for connections with laterally loaded dowel-type fasteners show pinched hysteresis loops under cyclic loads (Fig 1). Moreover, the achieved load at a certain displacement decreases under repeated loading-impairment of strength (see $\Delta F$ in Fig 1). Consequently, the

\footnotetext{
* Corresponding author
}

connection properties change with increasing number of load cycles and the energy dissipation capacity decreases significantly (Ceccotti 1995). To achieve continued energy dissipation under the repeated cycles of a longer earthquake, the connection displacement needs to be continually increased. However, the displacement capacity in CLT shear walls is limited in practice eg because of the limited interstory drift especially for shorter wall sections.

The reason for the pinched hysteresis behavior and the impairment of strength in connections with dowel-type fasteners (eg nails or screws) and a failure mode with two plastic hinges is the embedding deformation behavior of wood: the wood is plastically compressed under the action of a dowel-type fastener causing a cavity in the timber member [Fig 2(a)]. When the load direction is reversed, the fastener has to bridge the gap between the two plastic hinges without being 

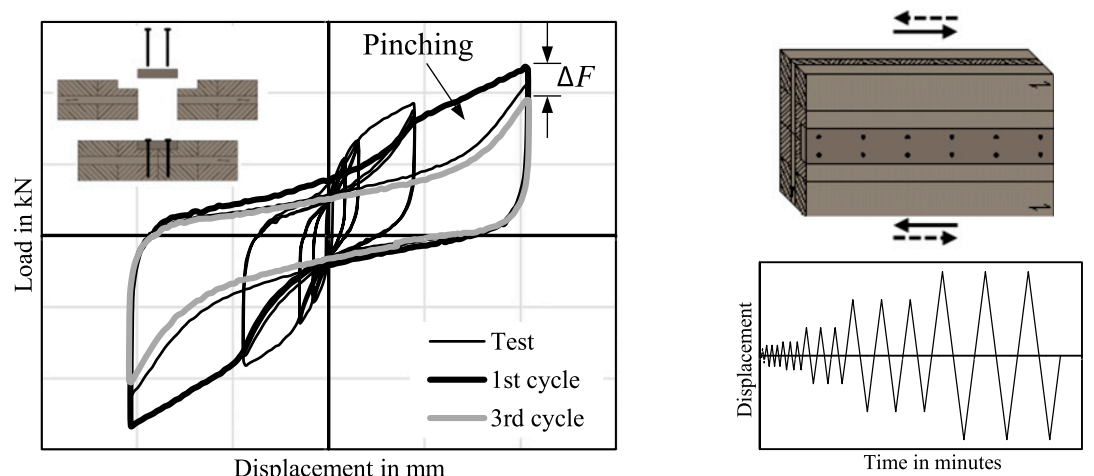

Figure 1. Pinched hysteresis loops and impairment of strength between the first load cycle and the third load cycle at the same displacement of traditional lap joint with nails under cyclic loading.

supported by wood until it touches the hole surface at the opposite side [Fig 2(b)]. Until then, the fastener mechanically acts as a fastener between two members with a gap in between [Fig 2(c)]. Because the load carrying capacity of a laterally loaded fastener decreases with increasing gap width, the load at a given slip also decreases at repeated load cycles. Hereby, the contribution of plastic embedding deformation of the wood is reduced as well, mainly the plastic bending of the fastener remains. If the fastener is repeatedly bent without touching the rim of the cavity, the energy dissipation is predominantly based on plastic fastener bending. Because of the inclination of the fastener axis, tensile forces develop in nails or screws leading to partial withdrawal out of the timber members and a rope effect increasing the load carrying capacity.

As a consequence of the observed behavior of laterally loaded dowel-type fasteners in timber members, the portion of the energy dissipation caused by metallic fasteners bending should be maximized whereas the contribution from plastic wood embedding deformation be minimized. This leads to less pinching and a reduced impairment of strength. Ideally, only plastic steel deformation should occur, whereas the timber embedding stresses remain in the elastic range.

For steel structures and structural concrete, practical solutions may be found in Dimitrov and Pocanschi (1985) and Pocanschi and Phocas (2003). A special device for timber structures, the U-shaped flexural plate (UFP), was proposed by Kelly et al (1972) and Iqbal et al (2007) (see Fig 3). Another possibility to reduce the embedding stress and thus plastic embedding deformation and to increase plastic fastener bending moments is to increase the contact area between fastener and timber. This means increasing the width of the metallic fastener but not the thickness, ultimately leading to steel plates as fasteners (Fig 4). To maximize the contribution from steel plate bending, a gap is arranged between the two timber members to be connected. First, tests were

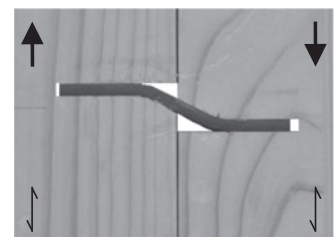

(a)

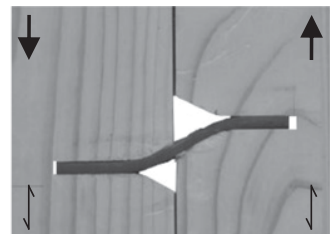

(b)

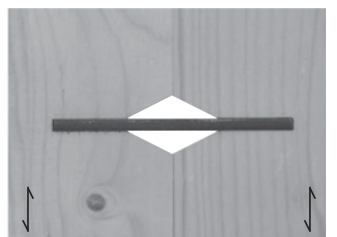

(c)

Figure 2. Cavities resulting from reversed load cycles in timber-to-timber connections with dowel-type fasteners. 

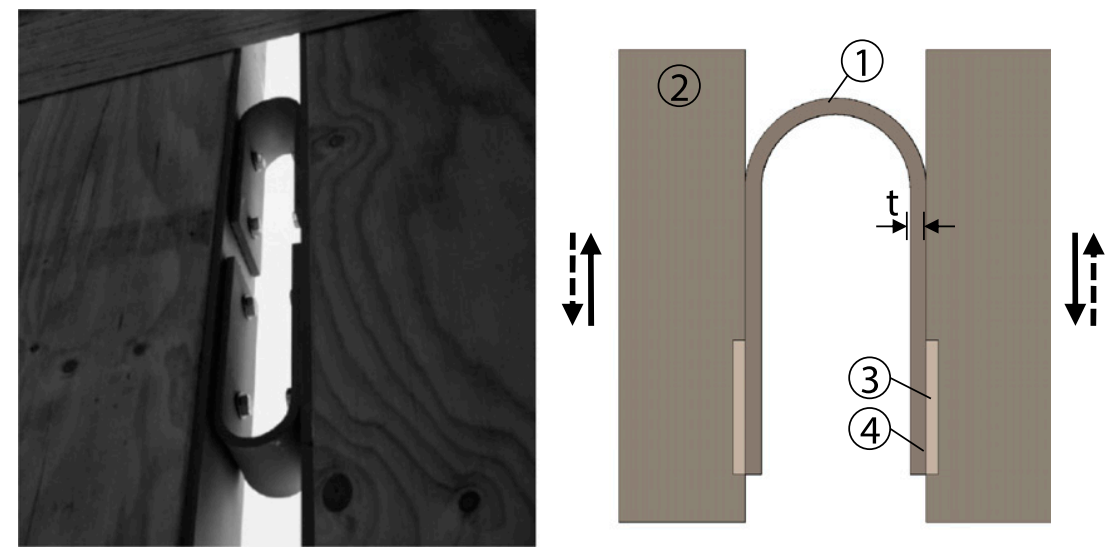

1 UFP

2 Timber members

3 Embedded plate

4 Site weld

$t$ Steel plate thickness

Figure 3. U-shaped flexural plates (UFP) after Kelly et al (1972); left: bolted connection between the UFP and embedded plate; right: welded connection between the UFP and embedded plate.

performed using timber members made of beech laminated veneer lumber (LVL) with very high embedding strength or compression strength parallel to the grain. The resulting energy dissipation of the tested connectors was very high compared with traditional timber connections with laterally loaded fasteners. Also, the hysteresis loops were hardly pinched, resulting in stable load-slip behavior under repeated loading.

The advantage of the steel plate fasteners compared with the UFPs is the easier fabrication of the connections; the disadvantage is the still existing—even though small—plastic embedding deformation of the timber. The reduction of the net cross-section of the timber members is not relevant for shear wall panels because the remaining crosssection for vertical or out-of-plane loads is entirely sufficient.

\section{MATERIALS AND METHODS}

Based on these arguments, the steel plate fasteners were tested in CLT members. European softwood (Norway spruce) CLT according to European Technical Approval ETA-11/0210 was used for the specimens. The three-layer CLT had a symmetrical layup (40-20-40 $\mathrm{mm}$ ) with a total thickness of $100 \mathrm{~mm}$ and a ratio of four between

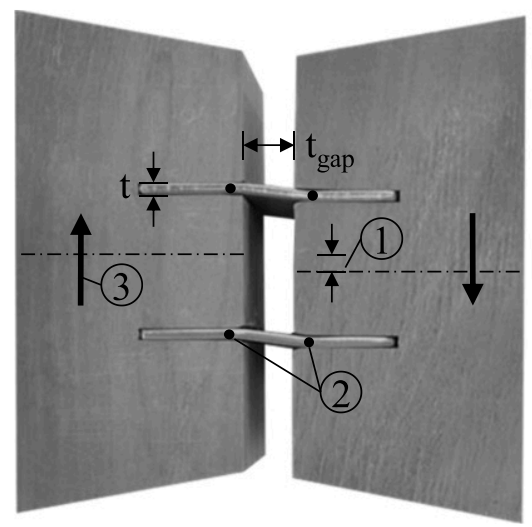

Figure 4. Dissipative connector according to Schmidt (2016).

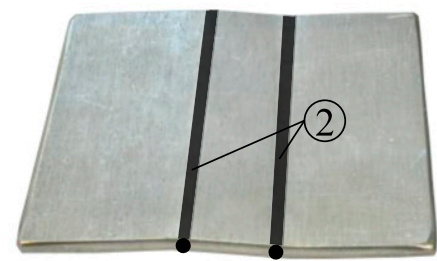

Plastic joint displacement Yield lines or plastic hinges Load direction Gap between timber members Steel plate thickness 
the sum of longitudinal and cross-layer thickness. Because of esthetic reasons, the edges between adjacent longitudinal layer boards are bonded. However, for the edge bonding a nonstructural adhesive is used, and hence the edge glue lines must not be used in the determination of the inplane shear strength of the CLT. The cross-layers are not edge bonded. The effective characteristic in-plane shear strength of the CLT according to ETA $11 / 0210$ is, hence, only $f_{\mathrm{v}, \mathrm{k}}=1.6 \mathrm{MPa}$ for the full cross-section. The average gross density of the CLT specimens is about $453 \mathrm{~kg} / \mathrm{m}^{3}$ with a coefficient of variation (COV) of $4.8 \%$. Table 1 shows the properties of the longitudinal layers determined after the connection tests. The steel plate fasteners were made of 6-mm thick mild steel S235JR with an average yield strength $f_{\mathrm{y}}=318 \mathrm{MPa}$ and an average tensile strength $f_{\mathrm{u}}=455 \mathrm{MPa}$.

Figure 5 shows the connection principle. The steel plate precisely fits into the CLT slots. The gap size $t_{\text {gap }}$ is defined by recesses in the CLT members. The penetration length $t_{\mathrm{e}}$ ensures a failure mode with two plastic hinges. Each specimen consists of three CLT elements connected at the edges by a steel plate. A small gap of $2 \mathrm{~mm}$ was left between the side and middle members of the connection to avoid friction. The middle member was loaded in both directions and the displacement was measured using four LVDTs. Six test series with varying gap size $t_{\text {gap }}$ between $0,10 . .50 \mathrm{~mm}$ were performed with two fasteners in each series. In each series, two tests with two steel plates in each specimen were performed. The load-displacement behavior was determined in cyclic tests according to EN 12512. Because the test program is based on the yield-deformation of the connection, after preliminary calculations the yield-deformation was estimated to be $3 \mathrm{~mm}$. The cyclic tests were performed until a permanent displacement $\Delta=18 \mathrm{~mm}$.

\section{RESULTS AND DISCUSSION}

Figure 6 (left) exemplarily shows a tested connection with two plastic hinges in the steel plate. The steel plate itself is shown in Fig 6 (right). Although steel plates with gap embedded in beech LVL with significantly higher compression strength showed defined yield lines under bending moments (see Fig 4), steel plates embedded in CLT with lower compression strength of the CLT longitudinal layer showed a plastic region (see Fig 6). The yield lines are continuous over the width of the steel plate, the reduced embedding resistance of the cross-layer in comparison with the longitudinal layers does not influence the bending deformation of the steel plate. The length of the plastic embedment area (see Fig 6, left) decreases with increasing gap size, $t_{\text {gap }}$.

Consequently, the portion of energy dissipation contributed by plastic steel deformation also increases with increasing gap size $t_{\text {gap }}$ even though the load carrying capacity of the connection decreases. The different load-slip behavior of connections with different gap sizes, $t_{\text {gap }}$, is shown in Fig 7 for gap size $t_{\text {gap }}=0 \mathrm{~mm}$ (left) and $t_{\text {gap }}=50 \mathrm{~mm}$ (right). Although pronounced pinching behavior is observed for gap size $t_{\text {gap }}=$ $0 \mathrm{~mm}$, gap size $t_{\text {gap }}=50 \mathrm{~mm}$ leads to nearly constant energy dissipation with repeated load cycles.

Table 2 shows the test results as mean values of two single tests for the six test series with different gap sizes. The decrease in load carrying

Table 1. Longitudinal layer properties of spruce cross-laminated timber.

\begin{tabular}{lcc}
\hline & Value & Coefficient of variation $(\%)$ \\
\hline Static modulus of elasticity in $\mathrm{MPa}$ & 10,800 & 20.6 \\
Compression strength parallel to the grain in $\mathrm{MPa}$ & 43.3 & 13.5 \\
Density $\left(\mathrm{kg} / \mathrm{m}^{3}\right)$ & 432 & 10.8 \\
Moisture Content $(\%)$ & 11.1 & 5.90 \\
\hline
\end{tabular}



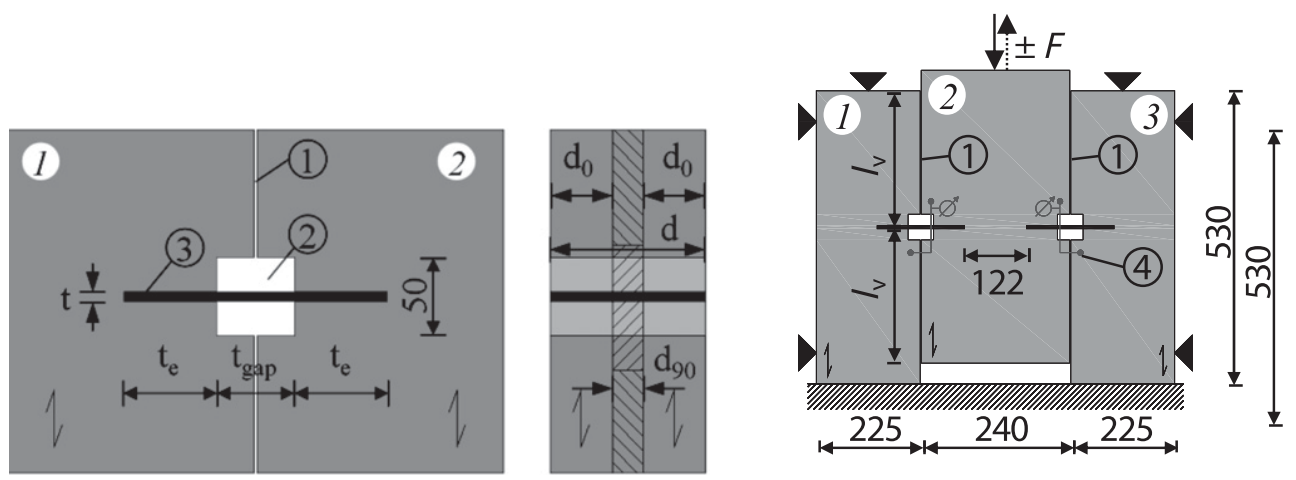

\begin{tabular}{llll}
\hline$t$ & Steel plate thickness $=6 \mathrm{~mm}$ & 1 & Gap $2 \mathrm{~mm}$ \\
$t_{\mathrm{e}}$ & Penetration length $=60 \mathrm{~mm}$ & 2 & Recess \\
$d$ & CLT thickness $=100 \mathrm{~mm}$ & 3 Steel plate connection with gap \\
$d_{0}$ & Longitudinal layer thickness $=40 \mathrm{~mm}$ & 4 & Four LVDTs on front and back side \\
$d_{90}$ & Cross layer thickness $=20 \mathrm{~mm}$ & $I_{\mathrm{v}}$ End distance $\geq 262 \mathrm{~mm}$ \\
\hline
\end{tabular}

Figure 5. Dissipative connector in cross-laminated timber (CLT) members (left) and test setup (right).

capacity and also impairment of strength with increasing gap size $t_{\text {gap }}$ is obvious. The load carrying capacity of a connection with $t_{\text {gap }}=$ $50 \mathrm{~mm}$ is only about $32 \%$ of the load carrying capacity of a connection with $t_{\text {gap }}=0 \mathrm{~mm}$. However, the impairment of strength could nearly completely be avoided by arranging a gap between the two CLT elements $(\Delta F=0)$. The equivalent hysteretic damping ratio increases with increasing gap size $t_{\text {gap }}$ for both the first and the third load cycle. Connections with $t_{\text {gap }}=$ $50 \mathrm{~mm}$ reached very high values of about $30 \%$ in comparison with traditional dowel-type fasteners. The decrease in load carrying capacity with increasing gap size may be compensated by a larger number of connectors, thereby ensuring quasi-stable energy dissipation behavior for many load cycles.

\section{Design Method}

Using the principles of the EYM-European Yield Model for dowel-type fasteners (Johansen 1949, the load carrying capacity of a connection with steel plates as fasteners is derived based on the compression strength parallel to the grain of the CLT longitudinal layers and the plastic bending moment capacity of the steel plate. It is assumed that the plastic region of the steel plate can be summarized to a yield line and the yield line to
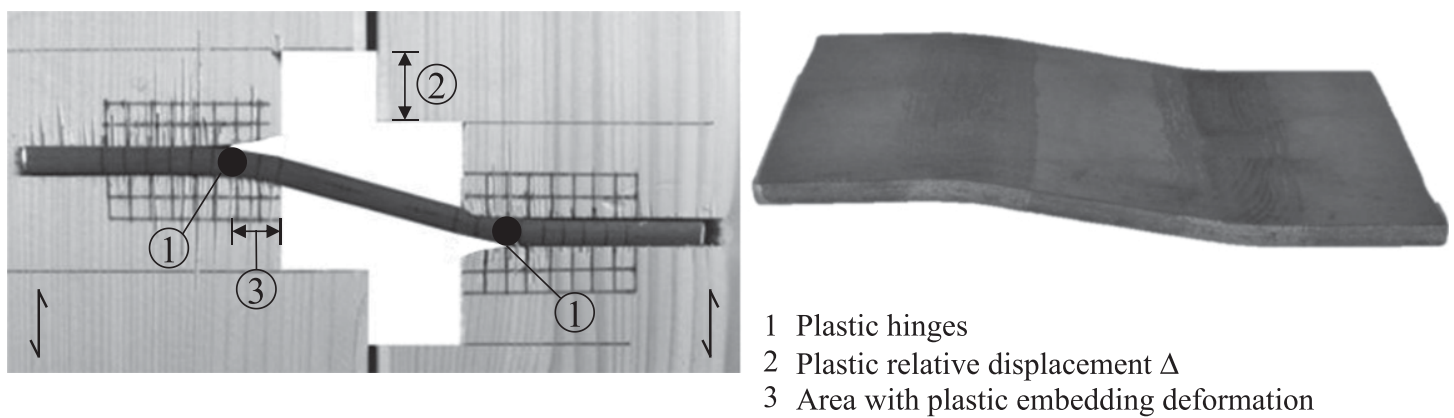

Figure 6. Loaded connection with dissipative connector in cross-laminated timber (CLT) members with $t_{\text {gap }}=50 \mathrm{~mm}$ (left) and deformed steel plate used in a connection (right). 


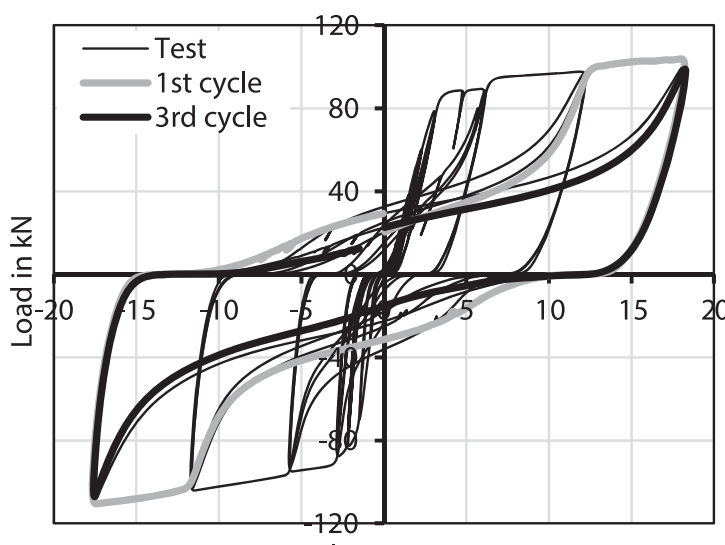

Displacement in $\mathrm{mm}$

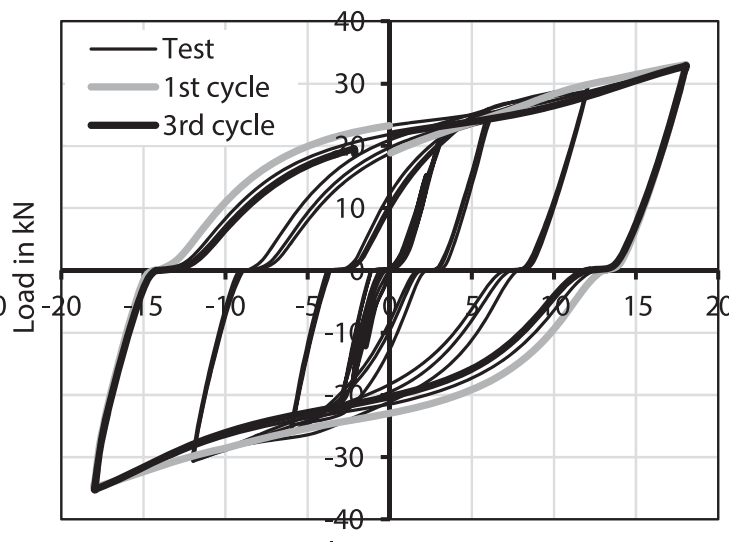

Displacement in $\mathrm{mm}$

Figure 7. Hysteresis loops with $t_{\text {gap }}=0 \mathrm{~mm}$ (left) and $t_{\text {gap }}=50 \mathrm{~mm}$ (right).

an ideal plastic hinge, respectively. Basically, there are six different possible failure modes of the connection, see Eqs 1-6. The load carrying capacity of the desired failure mode with two plastic hinges can be determined with Eq 6 . Figure 8 shows the mechanical model of the connection with two plastic hinges and a comparison with test results for different displacement levels. The calculated load carrying capacity according to $\mathrm{Eq} 6$ for connections with gap is reached in the tests already at displacement levels of $3 \mathrm{~mm}$ using $f_{\mathrm{y}}$ and at displacement levels of $12 \mathrm{~mm}$ using $f_{\mathrm{u}}$. The plastic bending moment resistance of the steel plate can be calculated according to $\mathrm{Eq} 7$.

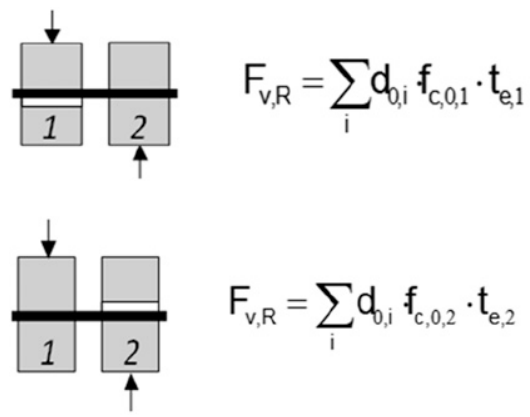

Table 2. Cyclic test results relating to the test setup with two steel plates in each specimen.

\begin{tabular}{|c|c|c|c|c|c|c|c|c|c|}
\hline \multirow[b]{3}{*}{ Test series } & \multirow[b]{3}{*}{$t_{\text {gap }}(\mathrm{mm})$} & \multirow{2}{*}{$\frac{F_{\max }(\mathrm{kN})}{1 \text { st cycle }}$} & \multirow[b]{2}{*}{$\Delta F_{1-3, \max }(\%)$} & \multicolumn{2}{|c|}{$v_{\mathrm{eq}}(\%)$} & \multirow{2}{*}{$\frac{F_{\max }(\mathrm{kN})}{1 \text { st cycle }}$} & \multirow[b]{2}{*}{$\Delta F_{1-3, \max }(\%)$} & \multicolumn{2}{|c|}{$v_{\mathrm{eq}}(\%)$} \\
\hline & & & & 1st cycle & 3rd cycle & & & 1st cycle & 3rd cycle \\
\hline & & \multicolumn{4}{|c|}{ Cycles at $18 \mathrm{~mm}$ slip } & \multicolumn{4}{|c|}{ Cycles at $12 \mathrm{~mm}$ slip } \\
\hline 1 & 0 & 108 & 4.07 & 20.4 & 12.5 & 101 & 3.54 & 24.4 & 13.3 \\
\hline 2 & 10 & 83.9 & 2.38 & 24.7 & 17.3 & 77.3 & 1.13 & 28.2 & 18.8 \\
\hline 3 & 20 & 63.9 & 1.32 & 28.0 & 21.8 & 58.0 & -0.52 & 30.2 & 22.5 \\
\hline 4 & 30 & 50.5 & 2.24 & 31.2 & 25.8 & 44.9 & -2.06 & 32.5 & 26.3 \\
\hline 5 & 40 & 40.0 & 0.78 & 33.0 & 28.7 & 35.0 & -2.68 & 33.0 & 29.0 \\
\hline \multirow[t]{2}{*}{6} & 50 & 34.1 & 0.04 & 32.2 & 27.8 & 29.3 & -3.53 & 31.1 & 27.5 \\
\hline & & \multicolumn{4}{|c|}{ Cycles at $6 \mathrm{~mm}$ slip } & \multicolumn{4}{|c|}{ Cycles at $3 \mathrm{~mm}$ slip } \\
\hline 1 & 0 & 92.6 & 3.05 & 21.3 & 10.0 & 82.7 & 5.39 & 6.90 & 2.98 \\
\hline 2 & 10 & 69.2 & 0.51 & 23.8 & 15.3 & 61.8 & 2.56 & 10.9 & 7.10 \\
\hline 3 & 20 & 50.3 & -3.25 & 23.6 & 17.1 & 43.7 & -0.11 & 8.47 & 6.08 \\
\hline 4 & 30 & 38.3 & -4.58 & 25.3 & 19.9 & 33.5 & -0.51 & 9.47 & 7.50 \\
\hline 5 & 40 & 29.5 & -5.70 & 25.0 & 21.3 & 26.1 & -0.34 & 8.48 & 6.89 \\
\hline 6 & 50 & 24.1 & -6.98 & 19.1 & 17.0 & 19.3 & -3.90 & 2.33 & 0.62 \\
\hline
\end{tabular}

$F_{\max }$, mean ultimate load at a certain displacement; $\Delta F_{1-3, \max }$, maximum impairment of strength; $E_{\mathrm{d}}$, dissipated energy in Nmm; $E_{\mathrm{p}}$, available potential energy in $\mathrm{Nmm} ; v_{\mathrm{eq}}$, mean equivalent hysteretic damping ratio: $v_{\mathrm{eq}}=E_{\mathrm{d}} /\left(2 \pi E_{\mathrm{p}}\right)$. 


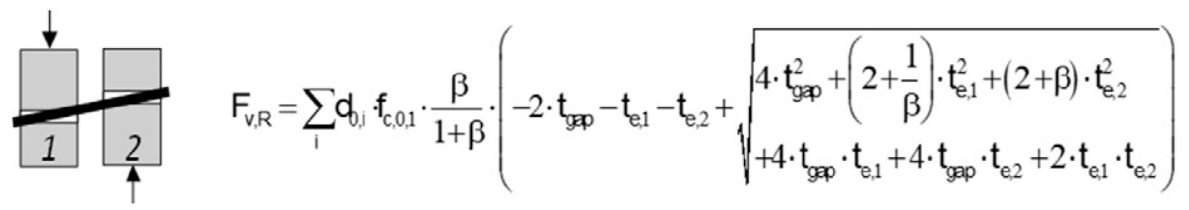

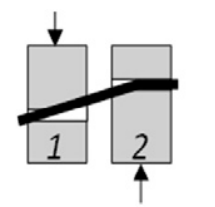

$F_{v, R}=\sum_{i} d_{0, i} f_{c, 0,1} \cdot \frac{2 \cdot \beta}{2+\beta}\left(-t_{g a p}-\frac{t_{e, 1}}{2}+\sqrt{t_{g a p}^{2}+t_{g a p} \cdot t_{e, 1}+\frac{t_{e, 1}^{2}}{2}+\frac{t_{e, 1}^{2}}{2 \cdot \beta}+\frac{2 \cdot M_{y}}{f_{c, 0,1} \cdot \beta \cdot \sum_{i} d_{0, i}}+\frac{M_{y}}{f_{c, 0,1} \cdot \sum_{i} d_{0, i}}}\right)$

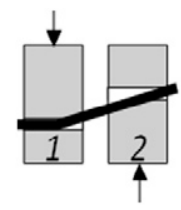

$F_{v, R}=\sum_{i} d_{0, i} f_{c, 0,1} \cdot \frac{\beta}{\frac{1}{2}+\beta}\left(-t_{g a p}-\frac{t_{e, 2}}{2}+\sqrt{t_{g a p}^{2}+\left(\frac{1}{2}+\frac{1}{2} \cdot \beta\right) \cdot t_{e, 2}^{2}+t_{g a p} \cdot t_{e, 2}+\frac{2 \cdot M_{y}}{f_{c, 0,1} \cdot \sum_{i} d_{0, i}}+\frac{M_{y}}{f_{c, 0,1} \cdot \beta \cdot \sum_{i} d_{0, j}}}\right)$

$F_{V, R}=\sum_{i} d_{0, i} \cdot f_{c, 0,1} \cdot \frac{1}{1+\beta}\left(\sqrt{\beta^{2} \cdot t_{g a p}^{2}+4 \beta \cdot(\beta+1) \frac{M_{y}}{\sum_{i} d_{0, i} \cdot f_{c, 0,1}}}-\beta \cdot t_{g a p}\right)$

Here, $d_{0, i}$ is the thickness of longitudinal layer $i$, $f_{\mathrm{c}, 0}$ is the compressive strength parallel to the grain, $t_{\text {gap }}$ is the gap size, $M_{\mathrm{y}}$ is the yield moment of the steel plate, $\beta=f_{\mathrm{c}, 0,2} / f_{\mathrm{c}, 0,1}$, and $t / b$ is thickness/width of the steel plate.

$$
M_{\mathrm{y}}=f_{\mathrm{y}} \cdot W_{\mathrm{pl}}=f_{\mathrm{y}} \cdot \frac{b \cdot t^{2}}{4} \text { and } M_{\mathrm{u}}=f_{\mathrm{u}} \cdot \frac{b \cdot t^{2}}{4}
$$

To ensure the desired failure mode with two plastic hinges, a minimum value for the penetration length $t_{\mathrm{e}, \min }$ in each timber member 1 and 2 is required.

The largest penetration length is required when high yield moment and low compression strength parallel to the grain coincide. Because the yield moment is generally larger than the lower 5\% quantile, an upper quantile of $M_{\mathrm{u}}$, calculated with

$$
\begin{aligned}
t_{\mathrm{e}, \min , 1}= & \left(2 \cdot \beta \cdot \sqrt{\frac{M_{\mathrm{y}}}{\sum_{i} d_{0, i} \cdot f_{\mathrm{c}, 0,1}}}+\sqrt{\frac{\sum_{i} d_{0, i} \cdot f_{\mathrm{c}, 0,1} \cdot \beta^{2} \cdot t_{\mathrm{gap}}^{2}+4 \cdot M_{\mathrm{y}} \cdot \beta^{2}+4 \cdot M_{\mathrm{y}} \cdot \beta}{\sum_{i} d_{0, i} \cdot f_{\mathrm{c}, 0,1}}}\right. \\
& \left.+2 \cdot \sqrt{\frac{M_{\mathrm{y}}}{\sum_{i} d_{0, i} \cdot f_{\mathrm{c}, 0,1}}}-\beta \cdot t_{\mathrm{gap}}\right) \cdot \frac{1}{\beta+1}
\end{aligned}
$$




$$
\begin{aligned}
t_{\mathrm{e}, \min , 2}= & \left(2 \cdot \beta \cdot \sqrt{\frac{M_{\mathrm{y}}}{\sum_{i} d_{0, i} \cdot \beta \cdot f_{\mathrm{c}, 0,1}}}+\sqrt{\frac{\sum_{i} d_{0, i} \cdot f_{\mathrm{c}, 0,1} \cdot \beta^{2} \cdot t_{\mathrm{gap}}^{2}+4 \cdot M_{\mathrm{y}} \cdot \beta^{2}+4 \cdot M_{\mathrm{y}} \cdot \beta}{\sum_{i} d_{0, i} \cdot f_{\mathrm{c}, 0,1}}}\right. \\
& \left.+2 \cdot \beta^{2} \sqrt{\frac{M_{\mathrm{y}}}{\sum_{i} d_{0, i} \cdot \beta \cdot f_{\mathrm{c}, 0,1}}}-\beta \cdot t_{\mathrm{gap}}\right) \cdot \frac{1}{\beta^{2}+\beta}
\end{aligned}
$$

the tensile strength, should be used to calculate the minimum penetration length $t_{\mathrm{e}, \mathrm{min}}$. Similarly, the $5 \%$ quantile of the compression strength perpendicular to the grain should be used. To verify the effect of varying compression strength and tensile strength values, a Monte Carlo simulation based on normally distributed strength values based on 192 wood compression tests parallel to the grain and steel tensile tests (three tests; assumed COV $13 \%$ according to Sadowski et al 2015) with 20,000 realizations for each gap size was carried out. To generate these results, simulated strength values were randomly chosen and Eqs 8 and 9 were evaluated. Figure 9 shows the results of the simulated penetration depth. The histogram in Fig 9 (left) shows the distribution of the simulated penetration length values for a steel plate connection with $t_{\text {gap }}=50 \mathrm{~mm}$. The distribution is

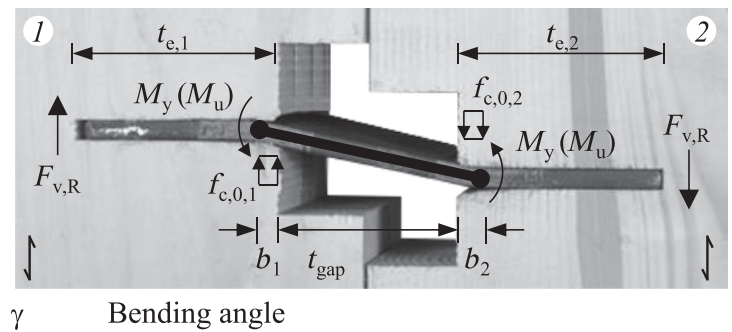

$b$

Length of plastic compression deformation in the first load cycle

$b_{1 \mathrm{st}, \mathrm{cycle}}=F_{\mathrm{v}, \mathrm{R}} /\left(\Sigma d_{0, i} \cdot f_{\mathrm{c}, 0}\right)$ close to a normal distribution. If $M_{\mathrm{u}, 95}$ and $f_{\mathrm{c}, 0,05}$ are used to determine $t_{\mathrm{e}, \mathrm{min}}$, the penetration length is close to the $98 \%$ quantile of the simulation results (see Fig 9 right).

However, after finishing the cyclic test program with several load cycles, a kind of wear out effect was observed resulting in the length of plastic compression deformation being two to four times as high as the calculated value " $b$ " according to $\mathrm{Eq}$ 10. This might be explained with lower compression strength values of longitudinal layers parallel to the grain under repeated loading up to the compression strength. Because the compression strength parallel to the grain of longitudinal layers is determined under monotonic load, which means the stress is applied in only one load cycle, the minimum penetration

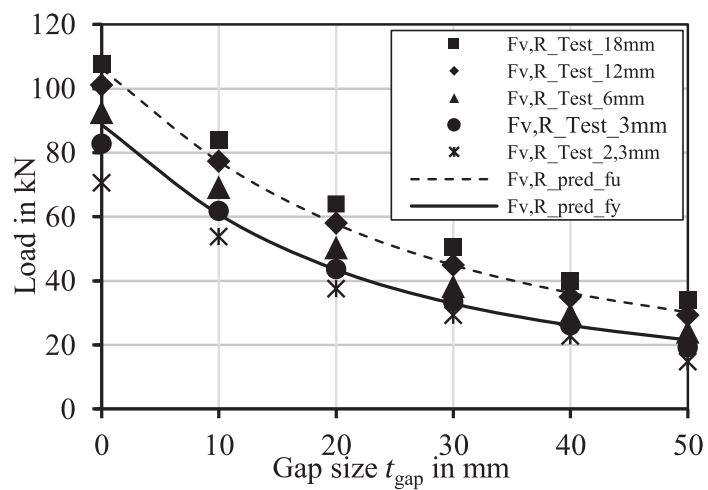

Figure 8. Mechanical model of the connection (left) and calculated load carrying capacity of two steel plates as mean values of two tests each gap size in comparison with test results (right). 

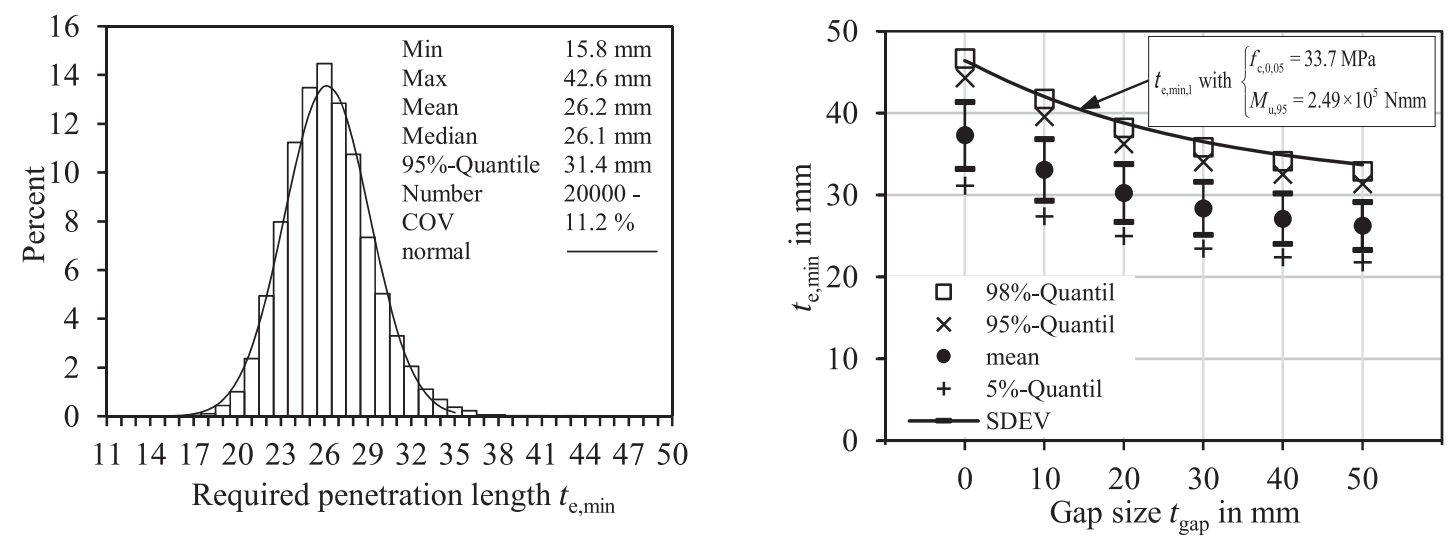

Figure 9. Simulated penetration length for $M_{\mathrm{u}}$. Distribution for $t_{\mathrm{gap}}=50 \mathrm{~mm}$ (left) and $t_{\mathrm{e}, \text { min }}$ depending on the gap size (right).

length according to Eqs 8 and 9 is only valid for the first load cycle in such a connection. Future work will consider this problem and an experimental study is planned to determine reduced compression strength values $\left(f_{\mathrm{c}, 0,05, \mathrm{red}}\right)$ under repeated load. Currently, Eqs 8 and 9 can be used to determine the penetration length for static loads.

\section{CONCLUSIONS}

Using steel plate fasteners in CLT edge connections with a gap, hence, allows influencing the behavior of the connection with the objective of basically avoiding pinching of hysteresis loops and impairment of strength under repeated loading.

For the dissipative shear wall joints, the typical pinching and impairment of strength of hysteresis loops at repeated loadings could nearly completely be avoided by arranging a gap between the CLT members around the steel plate.

After a strong earthquake, the steel plate connections will be loaded beyond their elastic limit. To assess the remaining dissipation capacity needed to resist aftershocks or further earthquakes, the cyclic test program according to EN 12512 was performed five to 10 times with each specimen. Increasing the number of load cycles leads to reduced load carrying capacity and less energy dissipation. However, for larger gap sizes the reduction of the mechanical properties is comparatively low (see Fig 10).

The behavior of both connections in shear walls will be studied in shear wall tests. Further research will particularly answer the following questions:

6 cycles $\geq \Delta=12 \mathrm{~mm} \quad 30$ cycles $\geq \Delta=12 \mathrm{~mm} \quad 60$ cycles $\geq \Delta=12 \mathrm{~mm}$

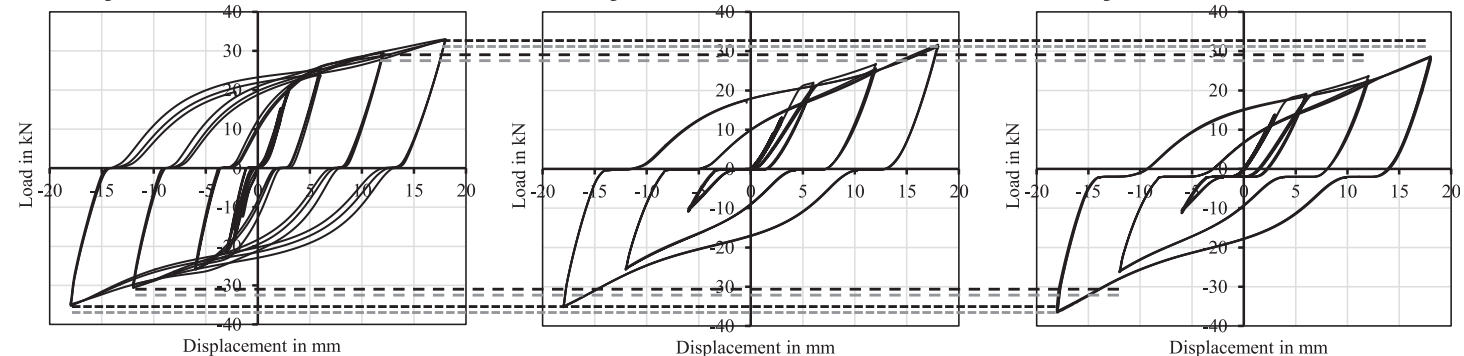

Figure 10. Load-displacement curves for a steel plate connection with $t_{\text {gap }}=50 \mathrm{~mm}$ after multiple cyclic loads. 
- Is the load-slip behavior of the dissipative steel plate connection significantly influenced by the rope effect?

- What is the influence of cyclic loading on the compression strength parallel to the grain of the CLT longitudinal layer in comparison with static loads?

The simple and cost-effective connection provides high energy dissipation and is easy to design.

\section{REFERENCES}

Ceccotti A (1995) Timber connections under seismic actions. STEP lecture C17, Timber Engineering STEP 1, Centrum Hout, Almere, The Netherlands.

Dimitrov N, Pocanschi A (1985) Wandscheiben mit dynamischer Anpassungsfähigkeit für Bauten in Erdbebengebieten. Bauingenieur 60:91-98.
Iqbal A, Pampanin S, Buchanan A (2007) Improved seismic performance of LVL post-tensioned walls coupled with UFP devices. 8th Pacific Conference on Earthquake Engineering, December 5-7, 2007, Singapore.

Johansen KW (1949) Theory of timber connections. IABSE 9:249-262.

Kelly JM, Skinner RI, Heine AJ (1972) Mechanisms of energy absorption in special devices for use in earthquake resistant structures. Bulletin of the New Zealand Society for Earthquake Engineering 5(3).

Pocanschi A, Phocas MC (2003) Kräfte in Bewegung - Die Techniken des erdbebensicheren Bauens. Teubner Verlag, Stuttgart, Leipzig, Wiesbaden.

Sadowski AJ, Rotter JM, Reinke T, Ummenhofer T (2015) Statistical analysis of the material properties of selected structural carbon steels. Struct Saf 53: 26-35.

Schmidt T (2016) Kontaktverbindungen zur Längsschubübertragung in den Schmalseiten von Brettsperrholzelementen. Doktorandenkolloquium Holzbau "Forschung und Praxis." Stuttgart, 1.-2.03.2016. Universität Stuttgart. 